\title{
Rapid Determination of Gold during Plating Operations by Portable X-Ray Fluorescence
}

\author{
Brandon J. Burnett1 ${ }^{*}$, Andrew Giles², Arthur L. Anderson3 ${ }^{3}$, Terry Darger ${ }^{3}$, \\ Edward Walker ${ }^{*}$ \\ ${ }^{1}$ Department of Chemistry, Snow College, Richfield, UT, USA \\ ${ }^{2}$ Department of Chemistry, Weber State University, Ogden, UT, USA \\ ${ }^{3}$ Gold Plating Services, Layton, UT, USA \\ Email: "brandon.burnett@snow.edu,
}

Received 26 September 2014; revised 11 November 2014; accepted 25 November 2014

Copyright (C) 2014 by authors and Scientific Research Publishing Inc.

This work is licensed under the Creative Commons Attribution International License (CC BY).

http://creativecommons.org/licenses/by/4.0/

(c) (i) Open Access

\begin{abstract}
We present the analysis of gold in plating solutions in the presence of several additive ions by portable X-ray fluorescence (XRF) revealing an optimum potassium gold cyanide concentration of 2 - $3 \mathrm{~g} / \mathrm{L}$ for maximum cathode efficiency. Additionally, we present the utility of XRF to determine the thickness of gold plated on copper substrates up to 6 microns.
\end{abstract}

\section{Keywords}

\section{Cathode Efficiency, Electrochemistry, Gold Plating, X-Ray Fluorescence}

\section{Introduction}

The process of hard electro-plating gold onto conductive surfaces electrochemically deposits a very thin layer of metallic gold over the surface of the item to be plated. This process is used widely in industry because it can impart some of the desired properties of the gold such as electrical conductivity, corrosion resistance, or decorative properties to the entire substrate being plated at a fraction of the cost of solid gold [1]-[4]. Additionally, the important mechanical properties of the substrate are often well maintained, creating a stronger material than solid gold.

While the general process of hard electro-depositing gold onto metal substrates is straightforward, attention to details in the process is necessary to ensure highly desirable products. Controlling levels of gold and other additives such as cobalt, nickel, potassium, and chromium in plating solutions is important because these concentrations affect the cathode efficiency, and thus the composition of the plated material [2]-[5]. Current methods for

${ }^{*}$ Corresponding authors.

How to cite this paper: Burnett, B.J., Giles, A., Anderson, A.L., Darger, T. and Walker, E. (2014) Rapid Determination of Gold during Plating Operations by Portable X-Ray Fluorescence. American Journal of Analytical Chemistry, 5, 1178-1183.

http://dx.doi.org/10.4236/ajac.2014.517125 
analysis of these additives include inductively coupled plasma, atomic absorption, and ultra -violet visible spectrophotometry [6]. While these methods are useful, they are inherently slow techniques, requiring sample preparation for analysis. Additionally, the instrumentation is often relatively large and stationary.

$\mathrm{X}$-ray fluorescence (XRF) is a technique that is employed for simultaneous qualitative and quantitative determination of elemental composition for a variety of solid and liquid samples [7] [8]. XRF techniques generally require minimal sample preparation and are non-destructive to the sample, making them attractive in a variety of industrial and commercial applications, such as the analysis of art, archaeological artefacts, electronics, coatings, pigments, etc. [3] [7] [8]. Portable hand-held XRF instruments provide fast elemental analysis with little to no sample preparation. XRF allows for the rapid determination of both the metal plate thickness and the composition of electro-plating solutions for total process control.

Herein, we report the utilization of a portable hand-held XRF instrument to determine the influence of gold concentration in plating solutions on the cathode efficiency of the plating cell in the presence of typical brightening agents including cobalt, nickel, potassium, and chromium. The optimum cathode efficiency of the plating process was revealed to be a potassium gold cyanide concentration of 2 - $3 \mathrm{~g} / \mathrm{L}$ under our experimental conditions. To our knowledge, this is the first example of utilizing XRF to determine cathode efficiency. Additionally, we report the utility of this XRF instrument in determining the thickness of gold layers plated on copper substrates up to 6 microns.

\section{Experimental}

Solid potassium gold cyanide (KAu(CN) $)_{2}$; PGC) (Gold Plating Services, Layton, Utah, USA) was reagent grade and used without further purification. Salts for brightening agents were all obtained from commercial sources and used without further purification. XRF data was obtained with a hand-held Thermo Scientific NITON XLt XRF instrument equipped with a low power $(1.0 \mathrm{~W}) \mathrm{X}$-ray tube and a silver anode target excitation source. Masses of the gold plated copper substrate were determined using a Mettler Toledo XP205 balance (accurate to $0.00001 \mathrm{~g})$.

Calibration of the XRF instrument was accomplished by dissolving solid PGC standard at concentrations of 0 - $12 \mathrm{~g} / \mathrm{L}$ (Figure 1). XRF intensities were obtained by integration of the emission spectra at the characteristic gold emission energies of 9.575 - $9.825 \mathrm{keV}\left(L_{\alpha}\right)$ and 11.325 - $11.575 \mathrm{keV}\left(L_{\beta}\right)$ (Figure 2).

Gold plating solutions were prepared by adding increments of $0.500 \mathrm{~g}$ of solid PGC into a $1.0 \mathrm{~L}$ standard plating solution containing commonly used brightening agents: nickel (385 ppm), chromium (153 ppm), and cobalt (1677 ppm). Each resulting solution was scanned by XRF.

Plating of gold was conducted on both sides of a copper substrate (1.00 in $\times 1.00 \mathrm{in} \times 0.040 \mathrm{in})$, giving a total plating area of $2.16 \mathrm{in}^{2}\left(13.9 \mathrm{~cm}^{2}\right)$. The substrate was prepared for plating by washing in $5 \% \mathrm{H}_{2} \mathrm{SO}_{4}$ solution, followed by successive washes in tap water and then distilled water. The dried substrate was then weighed, at-

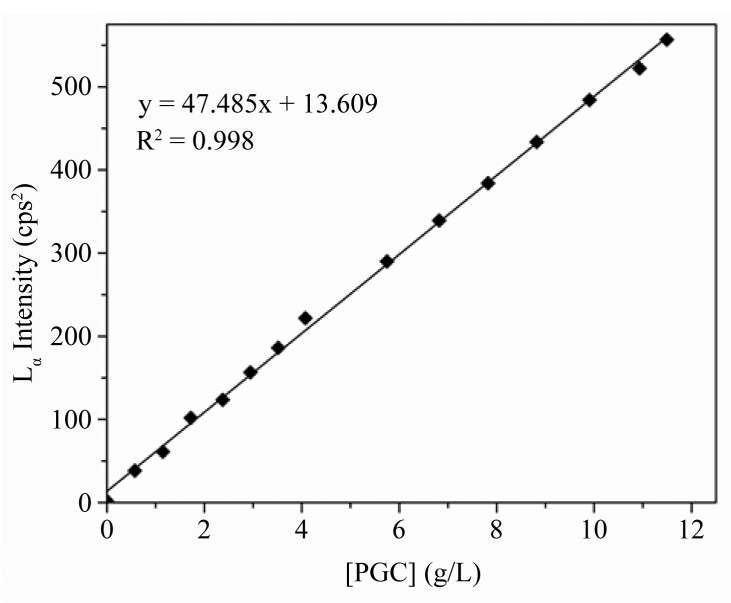

(a)

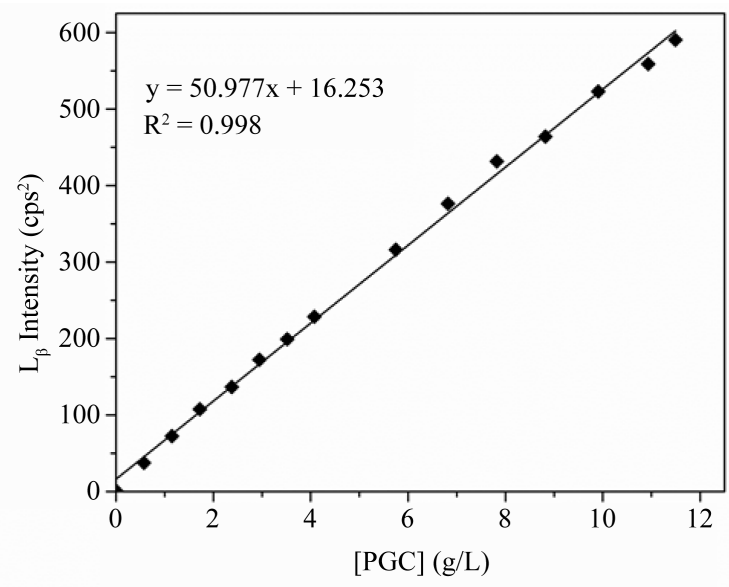

(b)

Figure 1. Calibration plots of gold (as PGC) in plating solutions. Intensities were obtained by integrating the gold (a) $L_{\alpha}$ and (b) $L_{\beta}$ signals. 


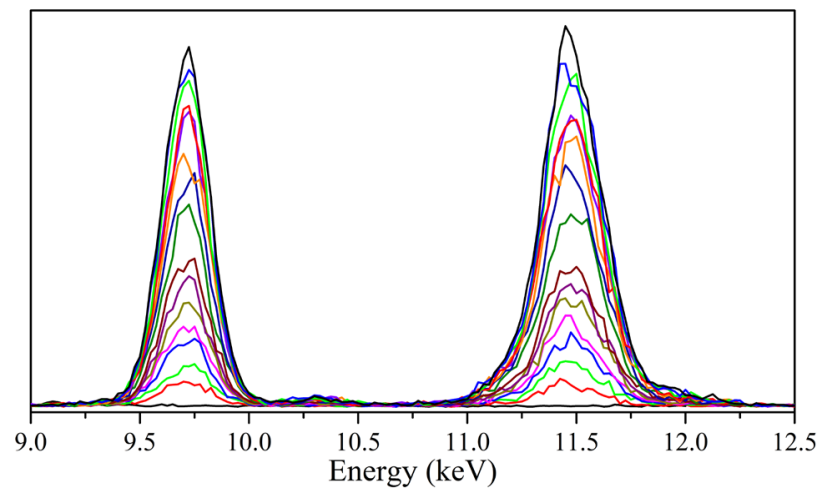

Figure 2. XRF spectra of gold $L_{\alpha}(9.725 \mathrm{keV})$ and $L_{\beta}(11.450$ $\mathrm{keV}$ ) emission energies in PGC solutions showing an increase in signal which correlates directly with an increase in gold concentrations from $0-12 \mathrm{~g} / \mathrm{L}$.

tached to the cathode lead of the cell and totally immersed in the stirred plating solution at $38^{\circ} \mathrm{C}$. A DC potential of $2.3 \mathrm{~V}$ was applied across the gold cathode and a stainless steel anode and adjusted slightly to maintain a constant current of $100 \mathrm{~mA}$ throughout the plating experiments. At five-minute intervals, the substrate was removed from the plating solution, rinsed with water and acetone, dried, and weighed again to determine the mass of gold that was deposited. The substrate was also analyzed by XRF and the resulting readings were compared to mass of gold deposited on the substrate. The substrate was then returned to the plating solution and the process was repeated.

The thickness of the deposited gold layer was calculated from the mass of the gold deposited across the total surface are of the coupon at each timed interval.

The cathode efficiency was calculated using the amount of gold plated onto the copper substrate as found by the gold $L_{\alpha}$ emission energy in the XRF spectra using the Equation (1). In this equation, $S_{L \alpha}$ is the gold $L_{\alpha}$ emission signal obtained by XRF, $A_{S}$ is the area of the substrate $\left(13.9 \mathrm{~cm}^{2}\right), \rho_{A u}$ is the density of gold $\left(19.30 \mathrm{~g} / \mathrm{cm}^{3}\right)$, $F$ is Faraday's constant, $A_{A}$ is the applied current $(0.100 \mathrm{~A}), M_{A u} s$ the atomic mass of gold $(196.97 \mathrm{~g} / \mathrm{mol})$, and $T$ is the time spent in the solution (300 s).

$$
\left(-2.00\left(S_{L_{\alpha}}\right)^{2}+71.12\left(S_{L_{\alpha}}\right)-34.45\right)\left(1.0 \times 10^{-4}\right)\left(A_{S}\right)\left(\rho_{A u}\right)(F) /\left(\left(A_{A}\right)\left(M_{A u}\right)(T)\right) \times 100
$$

\section{Results and Discussion}

XRF emission spectra of the gold emission bands are well-defined and resolved from copper and the brightening agents in the plating solution (Figure 3). Calibration plots were created from analyzing standardized PGC solutions by XRF, yielding linear results in the concentration range investigated (See Figure 1).

During the course of this study, it was observed that the cathode efficiency for gold deposition on a copper substrate plateaued at concentrations of PGC higher than $3 \mathrm{~g} / \mathrm{L}$ in the plating solution. As seen in Figure 4, at about 0 - $3 \mathrm{~g} / \mathrm{L}$ of PGC in the plating solution, the cathode efficiency increases significantly with PGC concentration (24.0\% increase between $0.39 \mathrm{~g} / \mathrm{L}$ and $2.76 \mathrm{~g} / \mathrm{L}$ ). However, above this concentration of PGC, the efficiency of gold deposition remains around 35\% - 38\%. Therefore, addition of excessive PGC in plating operations is unwarranted. Optimum plating efficiencies are achieved at PGC concentrations between $2-3 \mathrm{~g} / \mathrm{L}$, in which the cathode efficiency is above $30 \%$ and before it begins to plateau $(6.2 \%$ increase between $2.76 \mathrm{~g} / \mathrm{L}$ and $7.80 \mathrm{~g} / \mathrm{L}$ ). During the plating process, it was observed that the concentration of the brightening agents in the plating solution decreased minimally, compared to the rate of gold depletion. Only negligible amounts of the brighteners were observed on the gold plated copper substrate, which is consistent with earlier reports of using brighteners in gold plating processes [2] [5].

XRF was further used as a tool to investigate the thickness of gold plated onto the copper substrate. The intensity of the copper $\left(K_{\alpha}\right.$ and $\left.K_{\beta}\right)$ and gold $\left(L_{\alpha}\right.$ and $\left.L_{\beta}\right)$ emission frequencies changes at different rates as the gold thickness increases. A well-defined correlation is observed for both the increasing gold emission intensities and 


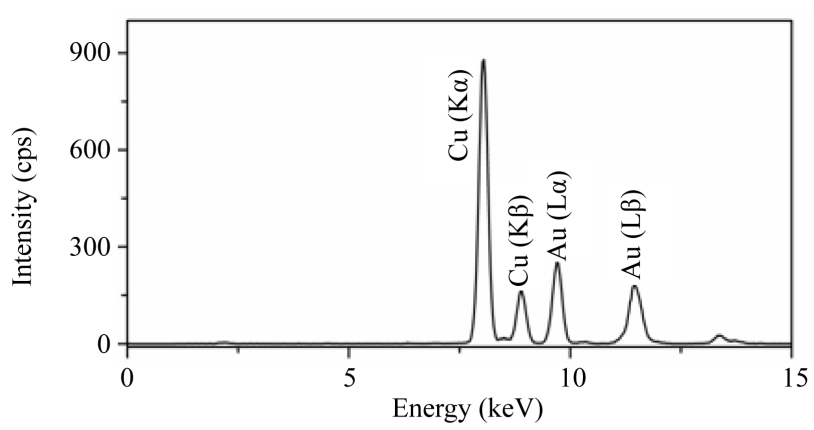

(a)

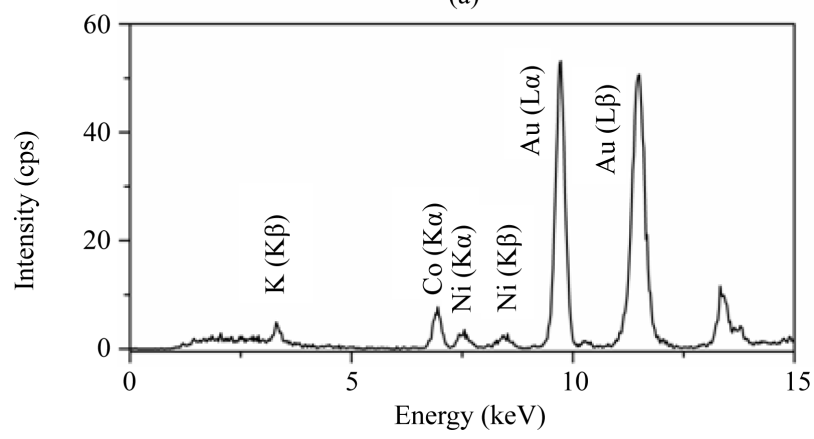

(b)

Figure 3. Experimental XRF emission spectra for (a) gold-plated substrate and (b) gold plating solution.

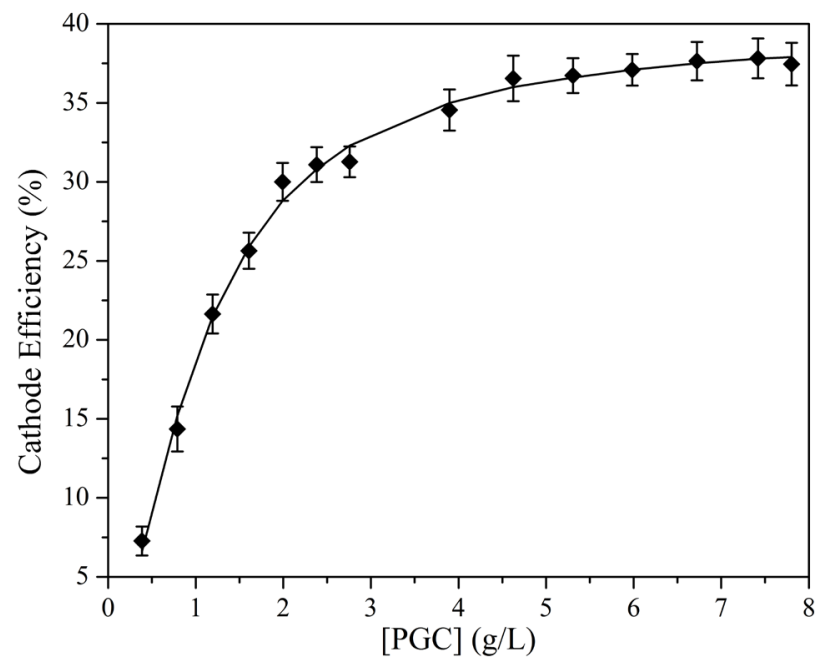

Figure 4. Cathode efficiency as a function of PGC concentration.

decreasing emission intensities from copper (see Figure 5 and Table 1). Any of these Foru emission energies can be used to determine the thickness of the gold plate as evidenced by the excellent correlation to second-degree polynomials in the calibration plots. Additionally, the difference between the copper emission intensities $\left(K_{\alpha}-K_{\beta}\right)$ and the gold emission intensities $\left(L_{\alpha}-L_{\beta}\right)$ offers additional options for determining the thickness of the gold plate (see Figure 6).

\section{Conclusions}

Hand-held, portable XRF spectrometers are an excellent choice for rapid analysis of gold in plating processes. These instruments are capable of quantitatively testing gold in liquid solutions, such as plating solutions in the 


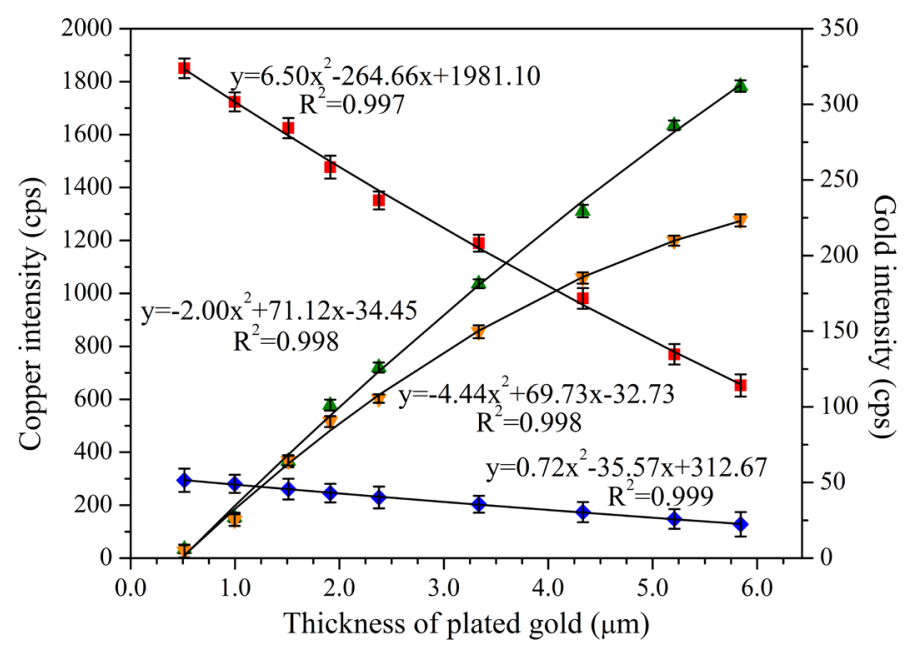

Figure 5. Calibration plot of copper and gold XRF emission intensities from plated substrate. Red squares (copper $K_{\alpha}$ ), blue diamonds (copper $K_{\beta}$ ), green triangles (gold $L_{\alpha}$ ), orange triangles (gold $L_{\beta}$ ).

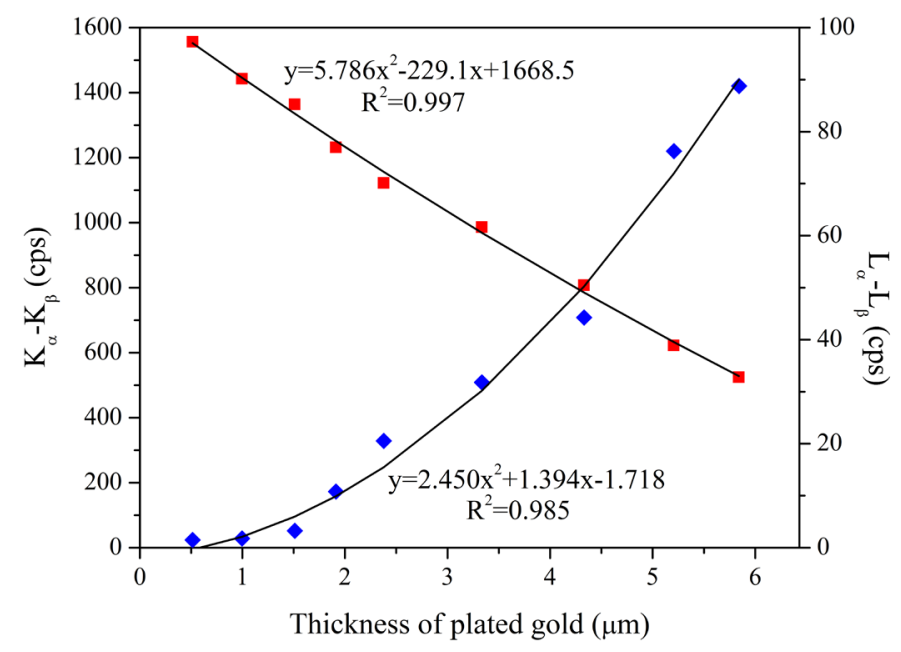

Figure 6. Calibration plot of the difference between copper emission signals $\left(K_{\alpha}-K_{\beta}\right)$ (red squares) and gold emission signals $\left(L_{\alpha}-L_{\beta}\right)$ (blue diamonds).

Table 1. Copper and gold XRF emission intensity as a function of thickness of plated gold on copper substrate.

\begin{tabular}{ccccccc}
\hline Sample & Mass $(\mathrm{mg})$ & Thickness $^{\mathrm{a}}(\mu \mathrm{m})$ & $\mathrm{Cu} K_{\alpha}(\mathrm{cps})$ & $\mathrm{Cu} K_{\beta}(\mathrm{cps})$ & $\mathrm{Au} L_{\alpha}(\mathrm{cps})$ & $\mathrm{Au} L_{\beta}(\mathrm{cps})$ \\
\hline 1 & 6.4 & 0.51 & 1850.45 & 294.05 & 6.02 & 4.55 \\
2 & 12.4 & 1.00 & 1723.23 & 280.68 & 26.94 & 18.18 \\
3 & 18.8 & 1.51 & 1624.63 & 260.62 & 64.12 & 44.37 \\
4 & 23.8 & 1.91 & 1477.05 & 245.60 & 101.12 & 70.33 \\
5 & 29.6 & 2.37 & 1351.17 & 229.08 & 126.03 & 95.50 \\
6 & 41.5 & 3.33 & 1189.69 & 203.45 & 181.40 & 109.61 \\
7 & 53.9 & 4.33 & 981.12 & 173.84 & 229.43 & 140.16 \\
8 & 64.8 & 5.21 & 769.92 & 147.84 & 286.07 & 199.83 \\
9 & 72.7 & 5.84 & 652.38 & 127.87 & 312.05 & 233.28 \\
\hline
\end{tabular}

${ }^{\mathrm{a}}$. Thickness calculated from the density as described above. 
presence of other elements such as nickel, chromium, and cobalt. In addition, the same instrument can be successfully utilized to measure the thickness of gold plated substrates such as copper in ranges that are commonly encountered in commercially plated products. Furthermore, by utilizing a portable hand-held XRF instrument, the analysis can be executed quickly. Indeed, analysis of both the PGC solution and the copper substrate during the plating processes were performed directly on the plating solution and plated substrate in a matter of $1-2$ minutes.

Cathode efficiency during plating was determined to be optimal only at 2 - 3 g PGC/L, with little or no increase in efficiency at higher concentration. This is important information to help improve plating processes while decreasing associated costs. This is especially important when considering the high cost of gold used in plating processes.

Based upon these results, we expect that portable hand-held XRF instruments will find additional applications for monitoring plating processes of other metals in addition to gold.

\section{Acknowledgements}

The authors wish to thank the Center for Chemical Technology at Weber State University for their support of this research effort. We also wish to thank Gold Plating Services of Layton, Utah for supplying PGC and standard gold plating liquids.

\section{References}

[1] For General Review of Hard Electro-Plating of Gold See (a) Reid, F.H. and Goldie, W. (1974) Gold Plating Technology, Electrochemical Publications, Ltd., Ayr.

[2] Wilkinson, P. (1986) Understanding Gold Plating. Gold Bulletin, 19, 75-81. http://dx.doi.org/10.1007/BF03214646

[3] Okinaka, Y. and Hoshino, M. (1998) Some Recent Topics in Gold Plating for Electronics Applications. Gold Bulletin, 31, 3-13. http://dx.doi.org/10.1007/BF03215469

[4] Dimitrijević, S., Rajčić-Vujasinović, M. and Trujić, V. (2013) Non-Cyanide Electrolytes for Gold Plating-A Review. International Journal of Electrochemical Science, 8, 6620-6646.

[5] Souter, I. (1974) Compatibility of Gold Deposits for Connector Contacts. IEEE Transactions on Parts, Hybrids, and Packaging, 10, 18-23.

[6] Pyrzyńa, K. (2005) Recent Developments in the Determination of Gold by Atomic Spectrometry Techniques. Spectrochimica Acta Part B, 60, 1316-1322.

[7] Mantler, M. and Schreiner, M. (2000) X-ray Fluorescence Spectrometry in Art and Archaeology. X-Ray Spectrometry, 29, 3-17. http://dx.doi.org/10.1002/(SICI)1097-4539(200001/02)29:1<3::AID-XRS398>3.0.CO;2-O

[8] Moioli, P. and Seccaroni, C. (2000) Analysis of Art Objects Using a Portable X-ray Fluorescence Spectrometer. X-Ray Spectrometry, 29, 48-52. http://dx.doi.org/10.1002/(SICI)1097-4539(200001/02)29:1<48::AID-XRS404>3.0.CO;2-H 
Scientific Research Publishing (SCIRP) is one of the largest Open Access journal publishers. It is currently publishing more than 200 open access, online, peer-reviewed journals covering a wide range of academic disciplines. SCIRP serves the worldwide academic communities and contributes to the progress and application of science with its publication.

Other selected journals from SCIRP are listed as below. Submit your manuscript to us via either submit@scirp.org or Online Submission Portal.
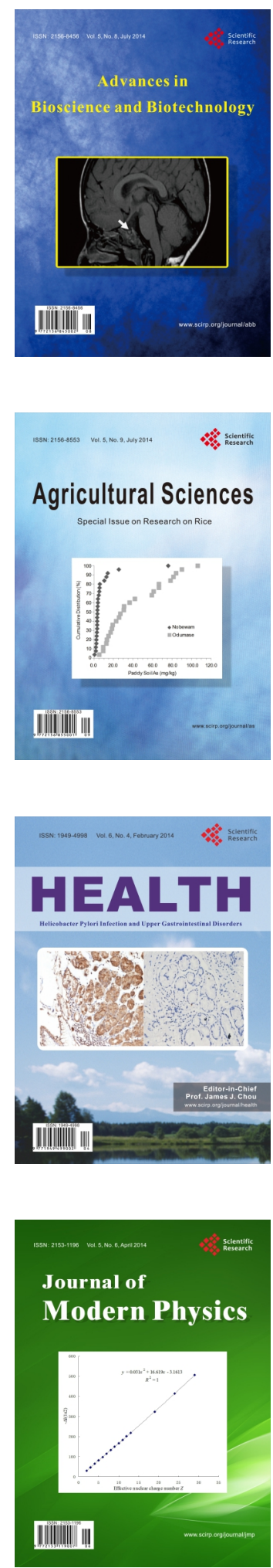
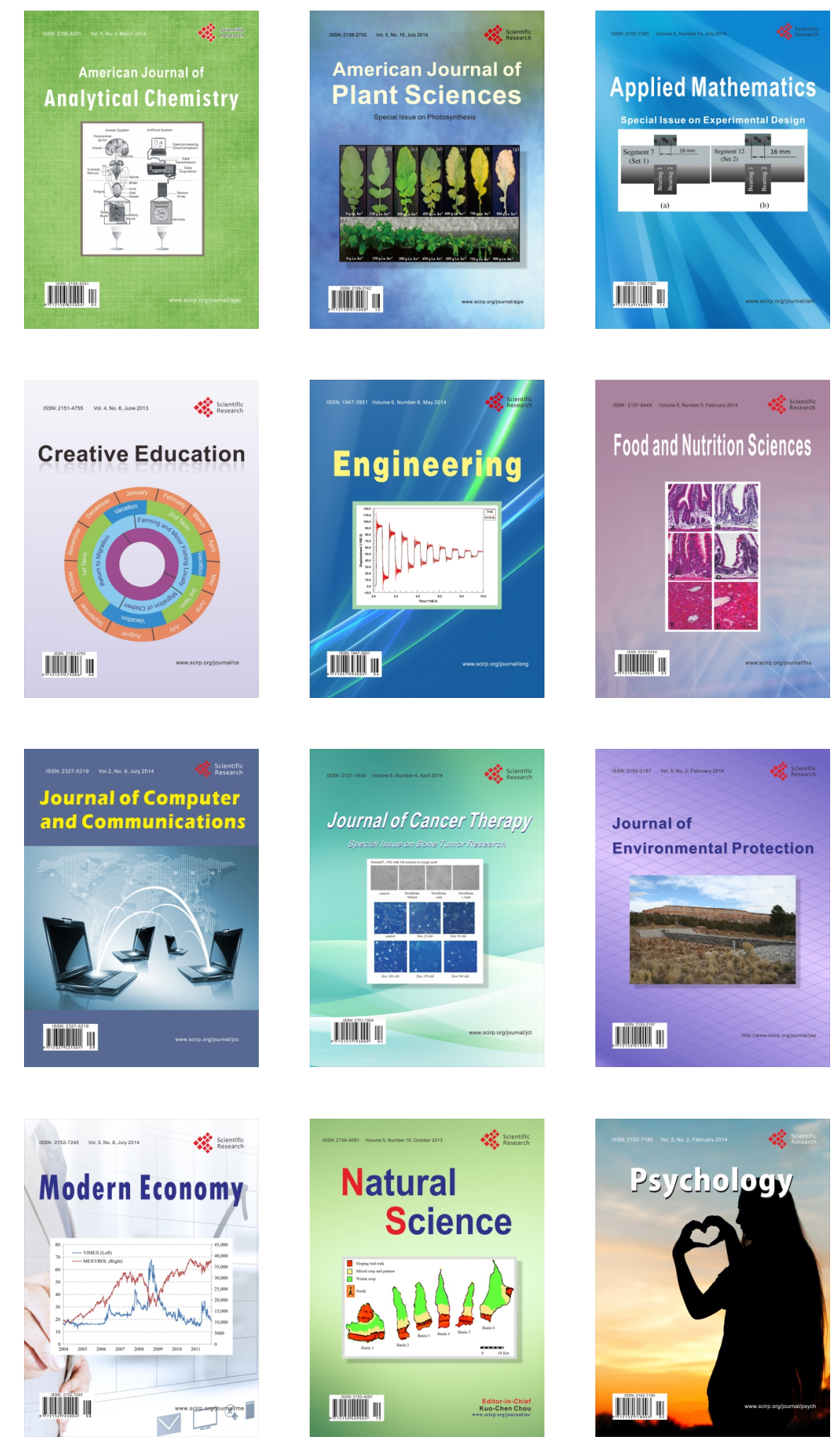